\title{
Supporting Information: A REDOR NMR Study of a Phosphorylated Statherin Fragment Bound to Hydroxyapatite Crystals
}

\author{
James M. Gibson, $\uparrow$ Vinodhkumar Raghunathan, $† \ddagger$ Jennifer M. Popham, $\ddagger$ Patrick S. Stayton, $\dagger^{\star}$ and \\ Gary P. Drobny $\ddagger^{*}$ \\ Departments of Bioengineering ${ }^{\dagger}$ and Chemistry ${ }^{\ddagger}$, University of Washington, Seattle, WA 98195.
}

\begin{abstract}
Materials and Methods
Sample Preparation

Protected amino acids and Fmoc-Gly-Wang resin were purchased from Calbiochem-Novabiochem Corp (San Diego, CA). Alpha $-{ }^{15} \mathrm{~N}$ labeled lysine was purchased from Cambridge Isotope Laboratories, Inc (Andover, MA). Hydroxyapatite $\left(55 \mathrm{~m}^{2} / \mathrm{g}\right.$ ) was synthesized by Allison Campbell's laboratory at Pacific Northwest National Lab as discussed previously ${ }^{1}$. Alpha- ${ }^{15} \mathrm{~N}$ labeled lysine was FMOC and BOC protected using a procedure from Wiejak et. al. ${ }^{2}$. Starting with a preloaded Fmoc-Gly-Wang resin (substitution $0.71 \mathrm{mmol} / \mathrm{gr}$ ), the $\mathrm{SN}-15$ peptide was synthesized on a Rainin PS3 automated solid phase peptide synthesizer (Protein
\end{abstract} Technologies, Inc.) where the solvent was $\mathrm{N}, \mathrm{N}$ dimethylformamide (DMF), the activator was $0.4 \mathrm{M}$ N-methyl morpholine in DMF and the deprotector was $20 \%(\mathrm{v} / \mathrm{v})$ piperidine in DMF. The peptide was cleaved from the resin using a 9.5 TFA:0.25 $\mathrm{H}_{2} \mathrm{O}: 0.25$ TIS (triisopropylisilane) solution following Method 3-18 described in the Novabiochem 2002/3 Catalog ${ }^{3}$. Using a Waters HPLC C-18 reverse phase column, the peptide was purified with an acetonitrile/water plus $0.1 \%$ TFA solvent system, was lyophilized, and then analyzed by MALDI mass spectrometry to establish composition and purity. The SN-15 peptide was physisorbed to hydroxyapatite by mixing a solution of 1.5-3 mM of peptide in a phosphate buffer with about $100 \mathrm{mg}$ of HAP. The $\mathrm{pH}$ of the mixture was adjusted to $\mathrm{pH} 7.4$ with $\mathrm{NaOH}$ and $\mathrm{HCl}$. The phosphate buffer was $100 \mathrm{mM} \mathrm{NaCl}, 40 \mu \mathrm{M} \mathrm{KCl}$, $1.4 \mu \mathrm{M} \mathrm{KH} \mathrm{PO}_{4}$ and $4.3 \mathrm{mM} \mathrm{Na}_{2} \mathrm{HPO}_{4}$. After $4 \mathrm{hrs}$ of mixing, the unbound peptide was separated from the peptide-HAP complex though centrifugation. The peptide-HAP sample was washed several times with buffer and was either then used as is or lyophilized for solid-state NMR studies.

\section{NMR Experiments}

The NMR experiments for the unbound and lyophilized samples were performed on an $11.7 \mathrm{~T}$ homebuilt spectrometer with Larmor frequencies of $500.32 \mathrm{MHz}$ for ${ }^{1} \mathrm{H}, 202.53 \mathrm{MHz}$ for ${ }^{31} \mathrm{P}$, and 50.74 $\mathrm{MHz}$ for ${ }^{15} \mathrm{~N}$. The experiments were performed using a $4 \mathrm{~mm}$ HXY triple-resonance Varian/Chemagnetics magic-angle-spinning probe, spinning at $8,000 \pm 1 \mathrm{~Hz}$, maintained by a homebuilt spinrate controller. All experiments were performed at room temperature. Sample ${ }^{15} \mathrm{~N}$ CPMAS NMR spectra for the unbound and bound peptide are shown in Figure $\mathrm{S} 1$, and sample ${ }^{31} \mathrm{P}$ CPMAS spectra for the unbound peptide and the peptide/HAP combination are shown in Figure S2. For all samples, the alternating $\pi$-pulse version of REDOR with XY-8 phase cycling was used, as demonstrated in Figure 1 in the main paper. The pulse lengths were as follows: $3 \mu$ s for the $1 \mathrm{H} \pi / 2$ pulse, $1 \mathrm{~ms}$ for the contact time, $12.2 \mu$ s for the ${ }^{15} \mathrm{~N} \pi$ pulses, and $11.5 \mu$ s for the ${ }^{31} \mathrm{P} \pi$ pulses. TPPM decoupling ${ }^{4}$ was utilized throughout all CPMAS and REDOR experiments at a field of $100 \mathrm{kHz}$ during the pulse sequence and $83 \mathrm{kHz}$ during acquisition. A pulse delay of 5 seconds was used in all experiments. For the unbound SN-15, data was acquired every eight rotor cycles, up to 160 total rotor cycles. For the first 80 rotor cycles, 128 transients were acquired for a total of 21 minutes per REDOR point. For the second 80 rotor cycles, 512 transients were acquired for a total of 84 minutes per REDOR point. For the bound peptide, REDOR points were taken at various numbers of rotor cycles as deemed necessary. In this case, 8192 transients were acquired for a total of 23 hours per REDOR point for those points below 96 rotor cycles. For the point at 96 rotor cycles, 16384 transients were acquired for a total of 46 hours.

The NMR experiments for the hydrated sample were performed on an 11.7 T Varian Spectrometer with a $5 \mathrm{~mm}$ HXY Doty probe. The pulse widths, spin-rates, and delays were held to the same standards as for the lyophilized samples. The temperature was held at $-40^{\circ} \mathrm{C}$ with an FTS cooler and nitrogen gas was used to spin the probe. 8192 transients were acquired for each data point, resulting in a total of 23 hours for each data point obtained on the hydrated sample.

\section{CPMAS Results}

Results for the ${ }^{15} \mathrm{~N}$ CPMAS of the unbound and bound peptides are shown in Figure S1, while the results for the ${ }^{31} \mathrm{P}$ CPMAS are shown in Figure S2. It is shown in Figure S1 that there is about a $2 \mathrm{ppm}$ shift of the lysine sidechain ${ }^{15} \mathrm{~N}$ spin upon binding. In Figure S2, it is demonstrated that there is about a 3 ppm difference between the peak observed for the phosphoserine sidechain and the peak observed corresponding to the HAP. Due to the width of the HAP peak, the phosphoserine sidechain is not observable in the HAP spectrum. One possible solution may be to shift the phosphoserine spectrum by substitution of an oxygen atom by a sulfur atom in the phosphate group. This substitution would result in about a $30 \mathrm{ppm}$ shift and would allow either for a REDOR experiment with that ${ }^{31} \mathrm{P}$ spin as the observe nucleus and the ${ }^{15} \mathrm{~N}$ as the dephasing nucleus, allowing for a careful measurement of the ${ }^{15} \mathrm{~N}-{ }^{31} \mathrm{P}$ REDOR dephasing due to intrapeptide effects or possibly even allow a frequency-selective REDOR $^{5}$ experiment to be performed to minimize all contributions from the phosphoserine sidechain. This synthesis is challenging, but we are exploring the possibility of such an experiment. We also need to address what effect the substitution of the sulfur atom for the oxygen atom has on the binding of the peptide fragment to the HAP crystals. 


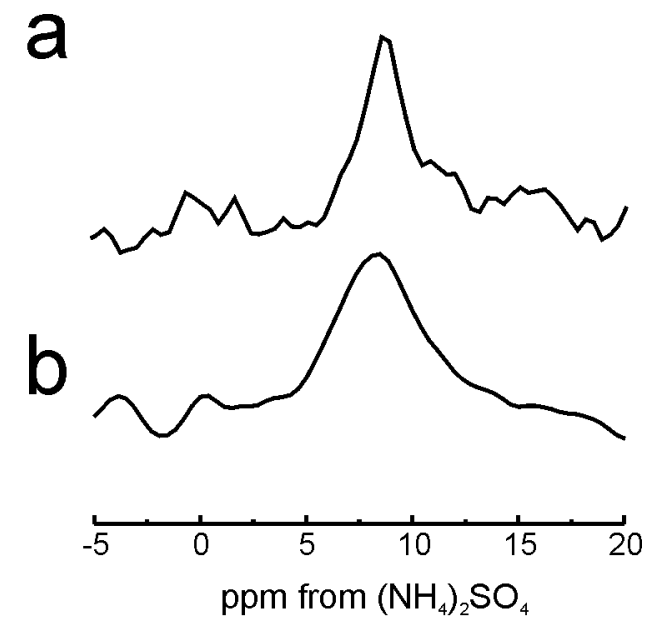

Figure S1: ${ }^{15} \mathrm{~N}$ CPMAS spectra were taken for both the (a) bound and (b) unbound peptide. About a 2 ppm shift difference between the two samples is noted. The unbound peptide CPMAS was obtained with 512 transients, while the bound peptide CPMAS was obtained with 8192 transients.

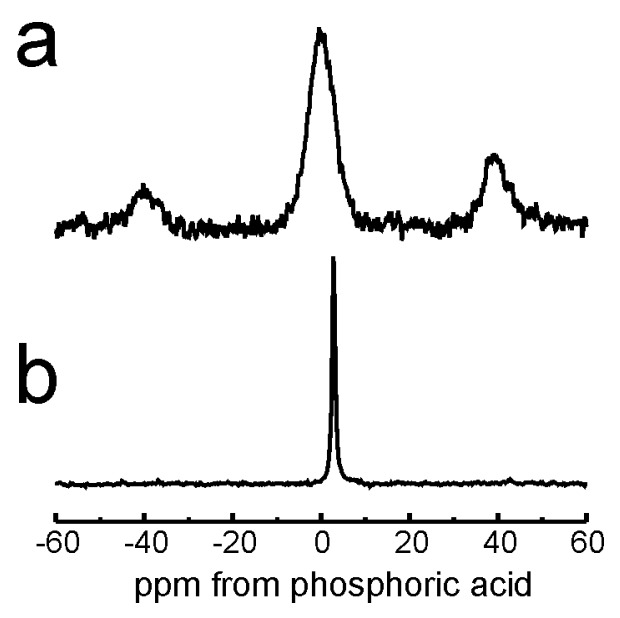

Figure S2: ${ }^{31} \mathrm{P}$ CPMAS spectra were taken for both the (b) unbound peptide and (b) SN-15 bound to HAP. The phosphoserine sidechain is not observable when combined with the HAP spectrum due to the small chemical shift difference and the width of the HAP peak.

\section{References}

(1) Long, J.R.; Shaw, W.J.; Stayton, P.S.; Drobny, G.P. Biochemistry, 2001, 40, 15451-15455.

(2) Wiejak, S.; Masiukiewicz E.; Rzeszotarska, Chem, Pharm. Bull., 1999, 47, 1489-1490.

(3) novabiochem 2002-2003 Catalog, pp. 3.14-3.19

(4) Bennett, A.E.; Rienstra, C.M.; Auger, M.; Lakshmi, K.V.; Griffin, R.G.; J. Chem. Phys., 1995, 103, 6951-6958.

(5) Jaroniec, C.P.; Tongue, B.A.; Herzfeld, J.; Griffin, R.G., J Am. Chem Soc., 2001, 123, 3507-3519. 
